\title{
Consumers' attributions and emotional responses to negative expectancy disconfirmation: Anger and regret
}

\author{
S.H Kim* \\ College of Business Administration, Chonnam National University, 300 \\ Yongbong-dong, Buk-gu, Gwang-ju 500-757, SOUTH KOREA \\ Ksh2851@chonnam.ac.kr
}

\begin{abstract}
This study examines the process by which consumer dissatisfaction is formed under negative expectancy disconfirmation with respect to consumer attributions and emotions. Although previous studies have demonstrated that negative expectancy disconfirmation can induce dissatisfaction of consumers, few studies have provided specific discussions on the mechanism underlying such dissatisfaction. This study focuses on consumers' cognitive and psychological responses to negative expectancy disconfirmation and examines the process by which consumer dissatisfaction is formed. For this, the study employs consumer attributions and emotional responses as antecedent variables for consumer dissatisfaction. Specifically, the study considers internal and external attributions as consumer attributions and anger and regret as their emotions. It further examines the mechanism underlying consumer dissatisfaction and behavior.
\end{abstract}

The results indicate that under negative expectancy disconfirmation, external attributions were more likely to induce anger than regret, whereas internal attributions were more likely to induce regret than anger. Consumers' dissatisfaction and behaviors, such as complaining and switching, were more likely to be influenced by anger than by regret.

*To whom all correspondence should be addressed.

\section{Introduction}

Consumers form expectations before buying a product. The situation in which the actual performance of a purchased product fails to meet the expectations is referred to as negative expectancy disconfirmation. Negative expectancy disconfirmation is more likely to induce consumers to make attributions (Folkes, 1984; 1988; Hastie, 1984; Weiner, 2000) than positive expectancy disconfirmation (Gendolla \& Koller, 2002). These attributions lead to emotional responses (Gendolla \& Koller, 2002; Weiner, 2000).

Studies on the relationship between attributions and emotional responses indicated that attributions can arouse emotional responses, suggesting that individuals feel as they think and that a change in thinking causes an emotional change. They also suggested that one of the most important types of cognition influencing emotions is causal attribution; that is, why a certain event has or has not occurred. This suggestion is based on the cognitive appraisal model of emotion. Thus, it can be said that attributions represent one of the most important cognitive appraisals arousing emotions (Lazarus, 1982; 1984; 1991).

This study is important because it demonstrated the possibility of consumer attribution under negative expectancy disconfirmation, consumer emotion according to attributions, and differential effect of these emotions on consumer dissatisfaction and behaviors. The purposes of this study are two-fold. The first is to examine the differential effect of consumer attributions of a purchase failure on anger and regret. The second is to examine the differential effect of anger and regret on consumer dissatisfaction and behavior.

\section{Literature review and hypotheses}

\section{Limitation of prior research and the differentiation of study}

This study aims to examine the following three aspects, which are being overlooked in the existing prior researches, and to empirically verify by proposing the following hypothesis. First, prior researches on satisfaction/ dissatisfaction, given the expectancy dis-confirmation, are suggesting a process called expectancy dis-confirmationemotion-satisfaction/dissatisfaction-behavior (Liao, Palvia, $\&$ Lin, 2010). However, consumers have a high possibility of experiencing emotion through grasping a cause for expectancy dis-confirmation, rather than experiencing emotion, due to simple expectancy dis-confirmation. That is, the possibility results because consumer emotion is indicated as the result of causal inference on the nonachievement of the desired goal, rather than being indicated by non-achievement in a goal. Accordingly, there is a need of a consideration on the consumer attribution process under expectancy dis-confirmation, and on consumers' diverse responses, which are engendered by this attribution. For this, the aim is to divide consumer attribution under expectancy dis-confirmation into internal attribution and external attribution, and to examine the influence of this attribution upon consumer emotion. This will be suggested in 
Hypothesis 1. Second, the empirical researches were performed on the effects of regret and disappointment, which are customers' negative emotional experiences caused by performance, failing to reach the expectation (Huefner \& Hunt, 2000; Gregoire \& Fisher, 2008). However, many researches were not performed on influence in anger, which is experienced by customers due to failure, upon customer dissatisfaction and behavior. In particular, the research on the differential influence of regret and anger upon customer response was short. Regret and anger may be varied despite their influence upon consumer response because of the difference in the cause and content of the experience. Third, researches on consumer emotion lack the detailed approach to emotional type. For example, it classified the emotions of being happy, pleasant, and enjoyable into positive emotion, and emotions of disappointment, regret, and anger into negative emotion. Moreover, it examined the influence of anger and regret upon consumer response from the overall perspective. However, the overall perspective in emotion does not consider the possibility that each emotion can have different effects on consumer behavior. The detailed approach to each emotion can be very useful in the sense of offering information on a cause for the occurrence of each emotion and its result. To overcome the limitations of the second and third prior researches mentioned earlier, this study aims to propose Hypothesis 2 and Hypothesis 3, and to suggest that the expectancy dis-confirmation leads to experiencing emotions, which are connected with morality and accountability, such as anger, and not just emotions, such as regret and disappointment. Also, this study aims to suggest different characteristics, which are possessed by each of these emotions, and to examine the differential influence in each of the emotions upon consumer response, without categorizing regret and anger as a dimension of negative emotions from the overall perspective as saying that both are negative emotions.

\section{Relationship of key constructs}

When consumers fail to obtain the desired results, they try to determine the cause of the failure. Attribution theory suggests that consumers' attitudes and responses toward some objects or events depend on inferences as to why certain behaviors bring about certain results, and moreover, how consumers' responses depend on whether they attribute behavioral outcomes to internal or external factors. Individuals experience diverse types of emotions through causal inferences (Carver, 2001; Gendolla \& Koller, 2002; Zeelenberg, Van Dijk \& Manstead, 1998). In terms of relationships between attributions and emotions, a number of studies have suggested that attributions precede emotions and the attribution process arouses emotions (Folks, 1984; Folks, Koletsky \& Graham, 1987; Machleit \& Mantel, 2001; McFarland \& Ross, 1982; Weiner, Russell \& Lerman, 1979; Weiner, 1985).

Consumers engage in buying behaviors in the expectation of certain product performance. They draw causal inferences about the cause of the failure and the responsibility for the gap between the actual product performance and their expectations. Such causal inferences influence consumers' emotional responses (Frijda, Kuipers \& Ter Schure, 1989; Machleit \& Mantel, 2001; Russell \& McAuley, 1986; Schachter \& Singer, 1962; Weiner, 1985) as well as their future behaviours (Schachter \& Singer, 1962). Consumers' emotions derive from causal inferences as to the attainment or non-attainment of the desired goal, not from the attainment or non-attainment of the goal. Thus, their emotions depend on attributions, and the types of emotions that consumers experience and the extent to which they experience them vary according to what they attribute a failure to (Weiner, 1974; 1985). Causal attributions, based on achievement in performing a task, can influence regret and anger (Wickens et al., 2011; Zucker \& Weiner, 1993). Regret and anger play important roles in the consumer decision-making process (Bougie, Pieters \& Zeelenberg, 2003; Cooke, Meyvin \& Schwartz, 2001; Hetts et al., 2000; Lerner \& Tiedens, 2006; McConnell et al., 2000).

Roseman, Antoniou and Jose (1996) suggested that regret is related to the attribution of responsibility. One's attribution of responsibility to oneself is likely to induce regret, which is closely related to the potential to control oneself; that is, believing that one could have controlled the result is likely to make one experience regret (Herrmann, Huber \&Braustein, 1999; Tsiros \& Mittal, 2000; Zeelenberg et al., 2000). Zeelenberg et al. (1998) suggested that the feeling that comes from one failing to make appropriate efforts or pay sufficient attention in order to obtain the desired result makes one more likely to attribute the non-attainment of the desired result to oneself, which ultimately increases the level of regret. This makes consumers attribute a failure to themselves; thus, they are more likely to experience regret than anger. Also, when consumers experience regret, they are likely to accept the product because they attribute a failure to themselves, even though it fails to meet their expectations. Therefore, dissatisfaction, offensive action, and revenge may be induced less by regret than by anger.

By contrast, external attributions are more likely to induce anger than regret (Bougie et al., 2003; Ortony, Clore \& Collins, 1988; Wickens et al., 2011). Under negative expectancy disconfirmation, anger is aroused if the undesirable result is attributed to the store that sold the product, the firm that manufactured it, or the product itself. Many studies (Batson et al., 2007; Betancourt \& Blair, 1992; Mauro, Sato \& Tucker, 1992; Smith \& Lazarus, 1993; Wickens et al., 2011) have indicated that anger is closely related to the responsibility and morality of the actor and occurs when a failure is attributed to others' immorality and irresponsibility (Averill, 1982; Batson et al., 2007; Lazarus, 1991; Hutcherson \& Gross, 2011; Lerner \& Tiedens, 2006). Under expectancy disconfirmation after a product purchase, external attributions of a failure can arouse anger because consumers believe that the manufacturer, the salesperson, and the vendor failed to fulfill their responsibility. That is, consumers believe that it is naturally the responsibility of the manufacturer, the salesperson, and the vendor to make and supply the best products for consumers. Thus, when a consumer perceives that a purchase failure is due to their failure to fulfill their responsibility (i.e., a lack of 
accountability), he or she is more likely to experience anger than regret, and thus, dissatisfaction will increase by anger than by regret. In addition, anger is one of the strongest types of emotions exerting fatal effects on social relationships (Lazarus, 1991; Lerner \& Tiedens, 2006). It can induce hostile behaviors, such as violence (Averill, 1982; Berkowitz, 1990), retaliatory action, and avoidance intentions (Bougie et al., 2003; Zinner et al., 2008). Thus, anger is a strong antecedent of negative behaviors, such as revenge and avoidance. Ultimately, anger is more likely to induce offensive and hostile behaviors, such as complaining and switching, than regret.

H1-1 Under negative expectancy disconfirmation, external attributions are more likely to induce anger than regret.

H1-2 Under negative expectancy disconfirmation, internal attributions are more likely to induce regret than anger.

H2 Under negative expectancy disconfirmation, anger is more likely to induce dissatisfaction than regret.

H3-1 Under negative expectancy disconfirmation, anger is more likely to induce complaining than regret.

H3-2 Under negative expectancy disconfirmation, anger is more likely to induce switching than regret.

A number of studies have examined the relationship between consumer dissatisfaction and behavior. In a purchase, satisfaction is related to repurchase intentions, word-of-mouth communication, and brand loyalty, whereas dissatisfaction is related to intentions to complain and demand compensation (Oliver, 1987). Thus, dissatisfaction, which is closely related to post-purchase phenomena, can be regarded as an important variable in the process of making a purchase. Complaining and switching behaviors are often suggested as outcome variables for consumer dissatisfaction. Consumers engaging in complaining behaviors complain to the store, the manufacturer, or the third party (Zeelenberg \& Pieters, 2004), and dissatisfied consumers are very likely to engage in such behaviors (Maute \& Forrester, 1993; Singh, 1988). In addition, dissatisfaction can induce switching behaviors (Newman \& Werbel, 1973). A number of studies have shown that dissatisfied consumers are very likely to switch brand, company, and store. Labarbera and Mazursky (1983) found that satisfaction/dissatisfaction is significantly correlated with repetitive behaviors. Sambandam and Lord (1995) demonstrated that dissatisfied consumers are less likely to revisit than satisfied ones. Based on these studies, the following hypotheses can be formulated.

\section{H 4-1 Dissatisfaction has positive influence on complaining.}

$$
\begin{aligned}
& \text { H 4-2 Dissatisfaction has positive influence on } \\
& \text { switching. }
\end{aligned}
$$

\section{Research model}

Figure 1 shows the research model in which consumer attribution is separated into external attribution and internal attribution, emotion is separated into anger and regret, and behavior is separated into complaining and switching. External attribution is more likely to induce anger than regret, and internal attribution is more likely to induce regret than anger. Anger is more likely to induce dissatisfaction, complaining, and switching than regret. Dissatisfaction has a positive influence on complaining and switching.

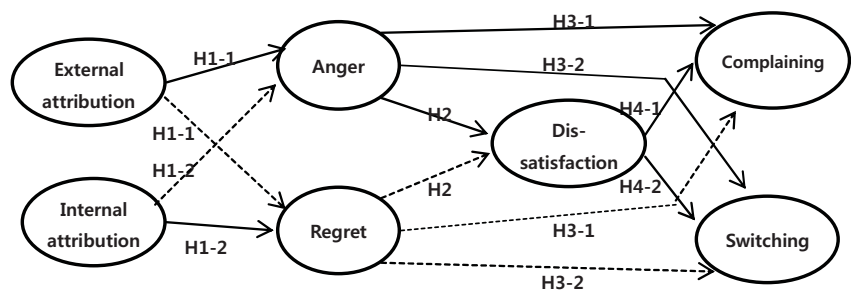

A solid line has a greater influence than a dotted line

Figure 1: The research model

\section{Research methodology}

\section{Data collection and procedures}

The data were obtained from undergraduate students (from grades 2 to 4) in South Korea. Questionnaires were distributed in several undergraduate business classes. The student's countries of origin are South Korea and China. Using a student sample provides equivalence of the sample even though the use of the sample limits generalizability (Ko, Roberts \& Cho, 2006). Also, undergraduates in their 20 s are being regarded as the critical target customers in diverse product categories. Many companies are striving to draw these people into customers. Even in the case of diverse shopping malls and brand agencies, the proportion of customers in their 20 s tends to increase gradually. In the real situation, these people are taking the lead in the sale. What examines the relationship among consumer attribution, emotion, and response in the expectancy disconfirmation situation targeting undergraduates in their 20s, who are patronage consumers, can be said to be great in the implication that can be offered to managers in the workinglevel aspect.

A memory-based survey method was adopted. This method is good to gather "naturally occurring responses" and is used much in consumer research (Schoefer, 2010; Zeelenberg \& Pieters, 2004). Respondents were asked to recall a particular incident in which the product they bought most recently failed to meet their expectations and then prepare a brief account of the incident, which was expected to remind them of the incident. They then were asked to complete a questionnaire. The product categories, which were primarily purchased by respondents, included clothes, shoes, sporting goods, accessory, cosmetics, books, disc, several kinds of fashion goods (necktie, belt, watch, etc.), and small electronic items. Also, the respondents were asked to briefly record a situation, which fell short of expectations. The 
typical situations involved bad touch and performance when applied to the case of cosmetics, the contents different from expectations and damage in the case of books and discs, bad wear ability and inferiority in the case of clothes or shoes, the design, which isn't suitable for clothing worn or lagging behind fashion in the case of necktie, accessory, and shoes, and product defects, bad performance and design in the case of watches and small electronic items.

The survey yielded a total of 361 responses. However, those with missing data were excluded. We obtained a final sample of 346 useable responses. Among the 346 respondents, 58\% were female. In addition, 50.9\% went shopping once a week; $42.2 \%$ went two or three times; $6.9 \%$ went four times or more; and $0.9 \%$ provided no response. $89 \%$ were Korean students, and the respondents' ages were between the ages of 19 to 28 , with approximately 60 of the respondents aged between 21 and 25 .

\section{Measures}

All of the constructs were operationalized as multi-item constructs. Scale items from previous studies of internal attribution, external attribution, anger, regret, and consumers' behavioral responses were obtained. Items for internal and external attributions were obtained from Russell (1982), Folkes et al. (1987) and Park and Moon (1990). These items were modified to reflect the context of the present study. The respondents rated each item on a sevenpoint Likert-type scale, ranging from "strongly disagree" (1) to "strongly agree" (7). The items for anger were obtained from Izard (1977), which was measured using a seven-point Likert-type scale, ranging from "none" (1) to "very much" (7). The items for regret were obtained from Kim (2005) and Zeelenberg and Pieters (2004), which were measured using a seven-point Likert-type scale, ranging from "none" (1) to "very much" (7). The items for dissatisfaction were obtained from Bougie et al. (2003) and Corsby and Stephens (1987), which were measured using a seven-point Likert-type scale, ranging from "none" (1) to "very much" (7). The items for consumers' behavioral responses (i.e., complaining and switching) were obtained from Kim (2005) and Zeelenberg and Pieters (2004), which were measured using a sevenpoint Likert-type scale, ranging from "none" (1) to "very much" (7).

\section{Data analysis}

Structural equation modelling (SEM) was used to validate the research model. Following Anderson and Gerbing's (1988) guidelines, data analysis was carried out in accordance with the two-stage methodology. First, confirmatory factor analysis (CFA) was conducted to evaluate the convergent and discriminant validity of the construct. Next, the causal structure of the model was tested using the structural equation analysis. LISREL 8.50 was used to perform these analyses.

\section{Measurement model}

Confirmatory factor analysis was conducted to determine whether the measurement items had appropriate properties to represent each construct. The results of the confirmatory analysis indicate acceptable construct validity and reliability for the measurement model. That is, $\chi 2$ was 369.6 with 168 $\mathrm{df}$, and the results for the fit indices $(\mathrm{CFI}=.92, \mathrm{GFI}=.93$, AGFI $=.91, \quad \mathrm{NNFI}=.92, \quad \mathrm{SRMR}=.046, \quad \mathrm{RMSEA}=.057)$ indicate that the measurement model provided a good fit to the data. All of the factor loadings for the constructs exceeded .65 , and the composite reliability of each scale exceeded the .70 threshold for acceptable reliability (Nunnally, 1978), indicating that the measures were internally consistent. Convergent validity is indicated when path coefficients from latent constructs to their corresponding indicators are significant (i.e., $t>1.96$ ). All items loaded significantly on their corresponding latent construct. All of the scales exceeded Nunnally's (1978) suggested Cronbach's alpha of .70. Table 1 shows the results; Table 2 shows the correlation matrices for the constructs.

\section{Structural model}

SEM (structural equation modeling) was then employed to investigate the relationships between the variables. To test the fit of the model, we considered $\chi 2$, comparative fit index(CFI), goodness of fit index(GFI), adjusted goodness of fit index(AGFI), the non-normed fit index (NNFI), the standardized root mean square residual (SRMR), and the root mean square error of approximation (RMSEA). Table 3 shows the results of the path analysis. As shown in Table 3, the results for all fit indices indicate that the model provided a good fit to the data ( $\chi 2$ with $174 \mathrm{df}=328.8 \mathrm{CFI}=.91$, GFI $=.92, \quad$ AGFI $=.90, \quad \mathrm{NNFI}=.93, \quad \mathrm{SRMR}=.049$, RMSEA=.062).

\section{Results}

\section{Effects of attributions on anger and regret (H1-1, H1-2)}

External attributions had significant positive effects on anger $(\beta=.647, \mathrm{t}=10.235, \quad \mathrm{p}<.01)$ and regret $(\beta=.318$, $\mathrm{t}=7.574, \mathrm{p}<.01)$. To examine the differences in the effects of external attributions on anger and regret (H1-1), we considered the differences in the $\chi 2$ value between the model with a constraint requiring the path coefficient from external attributions to anger to be identical to that from external attributions to regret and the model with no such constraint. The path coefficient from external attributions to anger showed a higher absolute value than that from external attributions to regret (external attributions $\rightarrow$ anger $=.647$ vs. external attributions $\rightarrow$ regret $=.318$ ). There were significant differences in these relationships $(\chi 2 \mathrm{~d}(1)=5.37$, $\mathrm{p}<.05)$. Thus, these results provide support for $\mathrm{H} 1-1$.

Internal attributions had significant positive effects on regret $(\beta=.534, \mathrm{t}=8.953, \mathrm{p}<.01)$ but no significant effects on anger 
$(\beta=.105, \mathrm{t}=1.452, \mathrm{~ns})$. To examine the differences in the effects of internal attributions on anger and regret (H1-2), we considered the differences in the $\chi^{2}$ value between the model with a constraint requiring that the path coefficient from internal attributions to anger be identical to that from internal attributions to regret and the model with no such constraint. The path coefficient from internal attributions to regret showed a higher absolute value than that from internal attributions to anger (internal attributions $\rightarrow$ anger $=.105$ vs. internal attributions $\rightarrow$ regret $=.534)$. There were significant differences in these relationships $(\chi 2 \mathrm{~d}(1)=11.52$, $\mathrm{p}<.01)$. Thus, these results provide support for $\mathrm{H} 1-2$.

\section{Effects of anger and regret on consumer dissatisfaction (H2)}

Both anger and regret had significant positive effects on consumer dissatisfaction $(\beta=.587, \mathrm{t}=9.745, \mathrm{p}<.01 ; \beta=.312$, $\mathrm{t}=7.697, \mathrm{p}<.01$ ). To examine the differences in the effects of regret and anger on dissatisfaction $(\mathrm{H} 2)$, we considered the differences in the $\chi^{2}$ value between the model with a constraint requiring that the path coefficient from anger to dissatisfaction be identical to that from regret to dissatisfaction and the model with no such constraint. The path coefficient from anger to dissatisfaction showed a higher absolute value than that from regret to dissatisfaction (anger $\rightarrow$ dissatisfaction $=.587$ vs. regret $\rightarrow$ dissatisfaction $=.312$ ). There were significant differences in these relationships $(\chi 2 \mathrm{~d}(1)=5.02, \mathrm{p}<.05)$. Thus, these results provide support for $\mathrm{H} 2$.

\section{Effects of anger and regret on consumer behavioral responses (H3-1, H3-2)}

Anger had a significant positive effect on complaining $(\beta=.476, t=8.159, p<.01)$; however, regret had no significant effect $(\beta=.122, \mathrm{t}=1.748, \mathrm{~ns})$. To examine the differences in the effects of regret and anger on complaining (H3-1), we considered the differences in the $\chi^{2}$ value between the model with a constraint requiring that the path coefficient from anger to complaining be identical to that from regret to complaining and the model with no such constraint. The path coefficient from anger to complaining showed a higher absolute value than that from regret to complaining (anger $\rightarrow$ complaining $=.476$ vs. regret $\rightarrow$ complaining $=.122$ ) There were significant differences in these relationships $(\chi 2 \mathrm{~d}(1)=9.43, \mathrm{p}<.01)$. Thus, these results provide support for H3-1.

Anger had a significant positive effect on switching $(\beta=.489$, $\mathrm{t}=8.274, \mathrm{p}<.01$ ), yet, regret had no significant effect $(\beta=.108, \mathrm{t}=1.475, \mathrm{~ns})$. To examine the differences in the effects of regret and anger on switching (H3-2), we considered the differences in the $\chi 2$ value between the model with a constraint requiring that the path coefficient from anger to switching be identical to that from regret to switching and the model with no such constraint. The path coefficient from anger to switching showed a higher absolute value than that from regret to switching (anger $\rightarrow$ switching $=.489$ vs. regret $\rightarrow$ switching $=.108)$. There were significant differences in these relationships $(\chi 2 \mathrm{~d}(1)=9.72$, $\mathrm{p}<.01)$. Therefore, these results provide support for H3-2.

\section{Effects of dissatisfaction on consumer behavioral responses (H4-1, H4-2)}

Consumer dissatisfaction had significant positive effects on complaining $(\beta=.547=9.258, \quad \mathrm{p}<.01) \quad$ and switching $(\beta=.536=8.957, \mathrm{p}<.01)$. Therefore, these results provide support for H4-1and H4-2.

\section{Discussion}

In this study, we examined the relationships between consumer attribution, emotional responses, and behavioral responses under negative expectancy disconfirmation after making a purchase. First, consumer attributions had differential effects on anger and regret (H1-1, H1-2). External attributions were more likely to induce anger than regret, whereas internal attributions were more likely to induce regret than anger, suggesting that consumers' emotions vary according to what they attribute a purchase failure to. Consumers are more likely to experience regret if they attribute the non-attainment of the desired goal to their failure in order to be a careful shopper, whereas they are more likely to experience anger if they attribute it to external factors. Second, anger and regret had differential effects on consumer dissatisfaction under negative expectancy disconfirmation (H2). That is, anger was more likely to induce dissatisfaction than regret. This suggests that the extent to which negative emotions influence dissatisfaction under a purchase failure vary according to the type of emotion. That is, consumers are likely to experience anger (which increases their dissatisfaction with the product) if they attribute a purchase failure to the manufacturer, the store, or the product, not to themselves, whereas they are likely to experience regret (which is less likely than anger to induce dissatisfaction) if they attribute it to the lack of their own effort, not to the manufacturer, the store, or the product. Third, anger and regret caused by negative expectancy disconfirmation had differential effects on consumer behavior (complaining/switching behaviors). Anger had positive effects on complaining and switching behaviors, whereas regret had negative effects on them (H3-1, H3-2). This result may be explained by the differences in behavioral features between anger and regret. That is, anger is likely to induce hostile behaviors toward others, whereas regret limits such behaviors through introspection. Anger, as a type of emotion caused by a failure to fulfill some responsibility, can lead to behavioral responses, such as complaining about the unfulfilled responsibility or avoiding contact (Averill, 1982; Berkowitz, 1990). By contrast, regret, which one experiences by attributing a wrong choice to one's own fault, is less likely to induce such behaviors than anger (Zeelenberg et al., 2000). 
Table 1: Measurement items, standardized factor loadings, construct reliability and Cronbach's Alpha

\begin{tabular}{|c|c|c|c|}
\hline Items & $\begin{array}{l}\text { Standardized } \\
\text { factor loading }\end{array}$ & $\begin{array}{l}\text { Construct } \\
\text { reliability }\end{array}$ & $\begin{array}{c}\text { Cronbach's } \\
\text { alpha }\end{array}$ \\
\hline $\begin{array}{l}\text { External attribution } \\
\text { The failure is attributed to the manufacturer of the product } \\
\text { The failure is attributed to the store that sold the product } \\
\text { The failure is attributed to the defects of the product. }\end{array}$ & $\begin{array}{l}0.768 \\
0.702 \\
0.697 \\
\end{array}$ & 0.77 & 0.75 \\
\hline $\begin{array}{l}\text { Internal attribution } \\
\text { I attribute the failure to myself. } \\
\text { The failure is the result of my fault. } \\
\text { I am responsible for the failure. }\end{array}$ & $\begin{array}{l}0.752 \\
0.689 \\
0.671 \\
\end{array}$ & 0.84 & 0.77 \\
\hline $\begin{array}{l}\text { Anger } \\
\text { Angry } \\
\text { Enraged } \\
\text { Mad }\end{array}$ & $\begin{array}{l}0.747 \\
0.721 \\
0.651\end{array}$ & 0.73 & 0.71 \\
\hline $\begin{array}{l}\text { Regret } \\
\text { Regret } \\
\text { Sorry } \\
\end{array}$ & $\begin{array}{l}0.842 \\
0.774 \\
\end{array}$ & 0.74 & 0.73 \\
\hline $\begin{array}{l}\text { Dissatisfaction } \\
\text { Dissatisfied } \\
\text { Displeased } \\
\text { Discontented } \\
\end{array}$ & $\begin{array}{l}0.812 \\
0.782 \\
0.732 \\
\end{array}$ & 0.86 & 0.83 \\
\hline $\begin{array}{l}\text { Complaining } \\
\text { Complain to external agencies such as consumer advocacy groups. } \\
\text { Complain to employees } \\
\text { Complain to the store } \\
\text { Complain to the manufacturer }\end{array}$ & $\begin{array}{l}0.758 \\
0.691 \\
0.702 \\
0.721\end{array}$ & 0.82 & 0.79 \\
\hline $\begin{array}{l}\text { Switching } \\
\text { I will buy this product less frequently than before. } \\
\text { I will switch to a competitor in the future. } \\
\text { I will no longer buy this product in the future. }\end{array}$ & $\begin{array}{l}0.764 \\
0.726 \\
0.714\end{array}$ & 0.77 & 0.74 \\
\hline
\end{tabular}

Table 2: Mean, standard deviation, and correlation matrices

\begin{tabular}{l|c|c|c|c|c|c|c}
\hline & $\mathbf{1}$ & $\mathbf{2}$ & $\mathbf{3}$ & $\mathbf{4}$ & $\mathbf{5}$ & $\mathbf{6}$ & $\mathbf{7}$ \\
\hline Mean & 3.75 & 3.02 & 3.52 & 3.71 & 3.64 & 3.31 & 3.43 \\
\hline S.D. & 1.46 & 1.41 & 1.42 & 1.37 & 1.32 & 1.43 & 1.35 \\
\hline 1. External attribution & 1.0 & & & & & & \\
\hline 2. Internal attribution & $-0.32^{* *}$ & 1.0 & & & & & \\
\hline 3. Anger & $0.58^{* *}$ & 0.12 & 1.0 & & & & \\
\hline 4. Regret & $0.21^{*}$ & $0.42^{* *}$ & $0.18^{* *}$ & 1.0 & & & \\
\hline 5. Dissatisfaction & $0.42^{* *}$ & $0.45^{* *}$ & $0.54^{* *}$ & $0.22^{*}$ & 1.0 & & \\
\hline 6. Complain & $0.52^{* *}$ & $0.38^{* *}$ & $0.33^{* *}$ & 0.13 & $0.49^{* *}$ & 1.0 & \\
\hline 7. Switching & $0.46^{* *}$ & $0.35^{* *}$ & $0.36^{* *}$ & 0.11 & $0.45^{* *}$ & $0.31^{* *}$ & 1.0 \\
\hline$*: \mathrm{p}<.01^{*}: \mathrm{p}<.05$ & & & &
\end{tabular}

\section{Implications for marketing}

The results have important implications for marketing. First, the results suggest that different types of emotions that consumers experience under negative expectancy disconfirmation have differential effects on consumer dissatisfaction. The extent to which consumers' emotions influence their responses varies according to the type of emotion. However, under negative expectancy disconfirmation, it varies according to the attribution target, and different types of emotions have differential effects on consumer dissatisfaction and behavior. Consumer dissatisfaction can be formed through the mediation of negative emotions, such as anger and regret. Thus, from a theoretical perspective, although previous studies did not discuss the differences in the extent to which different types of negative emotions influence consumers' responses, the results of the present study suggest that the extent to which negative emotions influence such responses varies according to the causes for negative emotions.

From a managerial perspective, managers have had high tendency of bisecting consumer emotion into an overall emotion, referred to as positivity/negativity. This is a better method in understanding the consumers' behavior than the overall approach, and the detailed approach to emotion is one of the issues that will need the interest of managers today. In the past, the focus was on finding elements that caused positive emotion and negative emotion, mainly through the overall approach to emotion. Such elements aimed to be managed. However, a problem of being possessed by the overall approach is stated to fail in considering the experience level and the influence level in each type of emotions, which are included in the category of 
positive emotion and negative emotion. This is due to the fact that positive emotion and negative emotion levels are decided by the total in each level of emotions, which comprise the positive emotional dimension and negative emotional dimension. Anger and regret are different in characteristic, content, and cause for occurrence, and have different influence upon the consumer response even if both are negative emotions. According to the overall approach, both anger and regret are involved in the category of negative emotion. The total of these emotions has negative effects on consumer response. Contrary to this, the detailed approach deeply considers characteristic, content, cause for occurrence, and influential level that each emotions has, and is addressing anger and regret as the independent emotion. Also, both anger and regret can be grasped not to have negative influence upon consumer response even if both are negative emotions. Accordingly, the management of emotion is possible in two aspects. Specifically, there is prevention, which is the pre-method, and recovery, which is the post-method. First, the prevention is a pre-method. Having grasped the detailed emotion that can be experienced by consumers after failure, such experience can be prevented in advance so that this emotion cannot be engendered. Regret is emotion that is experienced through internal attribution. Thus, there is a need of educating salespersons so that a consumer can purchase discreetly in advance. That is to say, there will be a need of educating salespersons so that he or she can conduct customer-oriented behaviour, not selling-oriented behavior.

\section{Table 3: Path analysis}

\begin{tabular}{|c|c|c|c|}
\hline \multicolumn{2}{|l|}{ Hypotheses } & $\begin{array}{l}\text { Path Coefficient } \\
\text { (t value) }\end{array}$ & $\Delta \chi^{2}$ \\
\hline $\begin{array}{l}\text { H1-1: } \\
\text { Under negative expectancy disconfirmation, } \\
\text { external attributions are more likely to induce anger than } \\
\text { regret. }\end{array}$ & $\begin{array}{l}\text { External attribution } \rightarrow \text { Anger } \\
\text { External attribution } \rightarrow \text { Regret }\end{array}$ & $\begin{array}{l}0.647(10.235)^{* *} \\
0.318(7.574)^{* *}\end{array}$ & $\begin{array}{l}\chi^{2} \mathrm{~d}(1)=5.37 \\
\mathrm{p}<.05\end{array}$ \\
\hline $\begin{array}{l}\text { H 1-2: } \\
\text { Under negative expectancy disconfirmation, internal } \\
\text { attributions are more likely to induce regret than anger. }\end{array}$ & $\begin{array}{l}\text { Internal attribution } \rightarrow \text { Anger } \\
\text { Internal attribution } \rightarrow \text { Regret }\end{array}$ & $\begin{array}{l}0.105(1.452) \\
0.534(8.953)^{* *}\end{array}$ & $\begin{array}{l}\chi^{2} \mathrm{~d}(1)=11.52 \\
\mathrm{p}<.01\end{array}$ \\
\hline $\begin{array}{l}\text { H } 2 \text { : } \\
\text { Under negative expectancy disconfirmation, anger is } \\
\text { more likely to induce dissatisfaction than regret. }\end{array}$ & $\begin{array}{l}\text { Anger } \rightarrow \text { Dissatisfaction } \\
\text { Regret } \rightarrow \text { Dissatisfaction }\end{array}$ & $\begin{array}{l}0.587(9.745)^{* *} \\
0.312(7.697)^{* *}\end{array}$ & $\begin{array}{l}\chi^{2} \mathrm{~d}(1)=5.01 \\
\mathrm{p}<.05\end{array}$ \\
\hline $\begin{array}{l}\text { H 3-1: } \\
\text { Under negative expectancy disconfirmation, anger is } \\
\text { more likely to induce complaining than regret. }\end{array}$ & $\begin{array}{l}\text { Anger } \rightarrow \text { Complaining } \\
\text { Regret } \rightarrow \text { Complaining }\end{array}$ & $\begin{array}{l}0.479(8.159)^{* *} \\
0.122(1.748)\end{array}$ & $\begin{array}{l}\chi^{2} \mathrm{~d}(1)=9.43 \\
\mathrm{p}<.01\end{array}$ \\
\hline $\begin{array}{l}\text { H } 3-2 \text { : } \\
\text { Under negative expectancy disconfirmation, anger is } \\
\text { more likely to induce switching than regret. }\end{array}$ & $\begin{array}{l}\text { Anger } \rightarrow \text { Switching } \\
\text { Regret } \rightarrow \text { Switching }\end{array}$ & $\begin{array}{l}0.489(8.274)^{* *} \\
0.108(1.475)\end{array}$ & $\begin{array}{l}\chi^{2} \mathrm{~d}(1)=9.72 \\
\mathrm{p}<.01\end{array}$ \\
\hline $\begin{array}{l}\text { H 4-1: } \\
\text { Dissatisfaction has a positive influence on complaining. }\end{array}$ & Dissatisfaction $\rightarrow$ Complaining & $0.547(9.258)^{* *}$ & - \\
\hline $\begin{array}{l}\text { H 4-2 : } \\
\text { Dissatisfaction has a positive influence on switching. }\end{array}$ & Dissatisfaction $\rightarrow$ Switching & $0.536(8.957)^{* *}$ & - \\
\hline
\end{tabular}

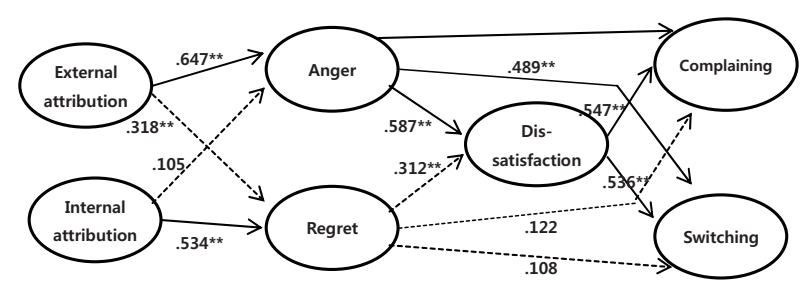

** Significant at 0.01

\section{Figure 2: Path analysis results}

In the anger case, companies should clarify the target market, determine what target markets expect from products, and the extent of their expectation, and also make efforts to meet those expectations. In addition, companies should attempt to meet consumers' expectations fully by appropriately managing expectations through realistic promises, not by raising them with promises that cannot be kept. Second, recovery is the post-method. Failure may take place because it is unable to offer a perfect product to customers even if the company attempts to prevent it. In this case, a plan for recovery is important. Regret doesn't have an influence upon consumer behavior, but has influence upon consumer dissatisfaction. Thus, recovery for this is needed. However, regret has a high possibility that a consumer will not express it to a company. Thus, a company needs to understand the cause and experience level of the regrettable emotion through a continuous consumer survey. In the case of anger, consumers who experienced such emotion have a possibility of expressing this positively to a company. 
Companies should analyse why their consumers experience anger and what is not fulfilled after a purchase despite the pre-purchase efforts by their consumers. In addition to this, prior research suggests the importance of authenticity in company's effort for recovery because anger is experienced through external attribution. Namely, empathy and understanding of a company for consumers, which have the authenticity toward consumers who experienced failure, are needed, not simply the material compensation.

\section{Limitations and future research}

This study has some limitations. First, we collected the data from college students, and thus, it is difficult to generalize the results to all consumer groups. Therefore, future research should consider diverse consumer groups in order to provide a better understanding of these results. Second, to measure negative expectancy disconfirmation, we focused only on determining whether such disconfirmation was experienced by the respondents. That is, we asked the respondents to recall a situation in which they experienced negative expectancy disconfirmation before examining other variables. However, the extent to which consumers experience negative expectancy disconfirmation is likely to vary across consumer segments. Thus, future research should first determine the level of expectancy disconfirmation and then examine consumer attributions, emotions (e.g., anger and regret), and responses. Third, we considered anger and regret separately, and thus, it is necessary to examine the causal relationship between these two emotions. That is, negative expectancy disconfirmation may induce consumers to experience anger, and this anger may influence regret in their selection of alternatives. Thus, future research should provide an in-depth analysis of the causal relationship between anger and regret. Fourth, we examined the relationships between experienced emotions, attributions, dissatisfaction, and behaviors under a purchase failure. However, it is also necessary to examine the relationships between the elements of positive emotions that consumers experience under a purchase success, attributions influencing such elements, consumer satisfaction, and consumer behavior. Such efforts should provide a better understanding of why consumers experience positive emotions when they make a successful purchase, which should be helpful for firms interested in developing strategies for fostering and reinforcing positive behaviors.

\section{References}

Anderson, J.C. \& Gerbing, D.W. 1988. 'Structural equation modeling in practice: A review and recommended two-step approach', Psychological Bulletin, 103(3): 411-423.

Averill, J.R. 1982. Anger and aggression: An essay on emotion. New York: Springer Verlag.

Batson, C.D., Kennedy, C.L., Nord, L., Stocks, E.L., Fleming, D.A., Marzette, C.M., Lishner, D.A., Hayes, R.E., Kolchinsky, L.M. \& Zerger, T. 2007. 'Anger at unfairness:
Is it moral outrage?', European Journal of Social Psychology, 37(6): 1272-1285.

Berkowitz, L. 1990. 'On the formation of anger and aggression: A cognitive-neoassocionistic analysis', American Psychologist, 45(4): 494-503.

Betancourt, H. \& Blair, I. 1992. 'A cognition (attribution)emotion model of violence in conflict situations', Personality and Social Psychology Bulletin, 18(3): 343-350.

Bougie, R., Pieters, R. \& Zeelenberg, M. 2003. 'Angry customers don't come back, they get back: The experience and behavioral implications of anger and dissatisfaction in services', Academy of Marketing Science, 31(4): 377-393.

Carver, C.S. 2001. 'Affect and the functional bases of behavior: On the dimensional structure of affective experience', Personality and Social Psychology Review, 5(4): 345-356.

Cooke, A.D.J., Meyvis, T. \& Schwartz, A. 2001. 'Avoiding future regret in purchase timing decisions', Journal of Consumer Research, 27(March): 447-459.

Crosby, L.A. \& Stephens, N. 1987. 'Effects of relationship marketing on satisfaction, retention, and prices in the life insurance industry', Journal of Marketing Research, 24(4): 404-411.

Folkes, V.S. 1984. 'Consumer reactions to product failure: An attributional approach', Journal of Consumer Research, 10(March): 398-409.

Folkes, V.S. 1988. 'Recent attribution research in consumer behavior: A review and new directions', Journal of Consumer Research, 14(March): 548-565.

Folkes, V.S., Koletsky, S. \& Graham, J.L.1987. 'A field study of casual inferences and consumer reaction: The view from the airport', Journal of Consumer Research, 13(March): 534-539.

Frijda, N.H., Kuipers, P. \& Ter Schure, E. 1989. 'Relations among emotions, appraisal, and emotion action readiness', Journal of Personality and Social Psychology, 57(2): 212228.

Gendolla, G.H.E. \& Koller, M. 2002. 'Surprise and motivation of causal search: How are they affected by outcome valence and importance?', Motivation and Emotion, 25(4): 327-349.

Gregoire, Y. \& Fisher, R.J. 2008. 'Customer betrayal and retaliation: When your best customers become your worst enemies', Journal of the Academy of Marketing Science, 36(2): 247-261.

Hastie, R. 1984. 'Causes and effects of causal attribution', Journal of Personality and Social Psychology, 46(1): 44-56. 
Herrmann, A., Huber, F. \& Braustein, C. 1999. 'A regret theory approach to assessing customer satisfaction when alternatives are considered', European Advertising Consumer Research, 4(1): 82-88.

Hetts, J.J., Boninger, D.S., Armor, D.A., Gleicher, F. \& Nathanson, A. 2000. 'The influence of anticipated counterfactual regret on behavior', Psychology and Marketing, 17(4): 345-368.

Huefner, J.C. \& Hunt, H.K. 2000. 'Consumer retaliation as a response to dissatisfaction', Journal of Consumer Satisfaction, Dissatisfaction and Complaining Behavior, 13(1): 61-82.

Hutcherson, C.A. \& Gross, J.J. 2011. 'The moral emotions: A social-functionalist account of anger, disgust, and contempt', Journal of Personality and Social Psychology, 100(4): 719-737.

Izard, C.E. 1977. Human emotions. New York: Plenum.

Kim, S.H. 2005. 'A study of consumers' regret and disappointment - consumers' information effort and expectancy disconfirmation', Proceedings of Korean Marketing Management Association Conference (Spring): 117-138. Busan, South Korea.

Ko, H., Roberts, M.S. \& Cho, C.H. 2006. 'Cross-cultural differences in motivations and perceived interactivity: A comparative study of American and Korean Internet users', Journal of Current Issues and Research in Advertising, 28(2): 93-104.

Labarbera, P.A. \& Mazursky, D. 1983. 'A longitudinal assessment of consumer satisfaction/dissatisfaction: The dynamic aspect of the cognitive process', Journal of Marketing Research, 20: 393-404.

Lazarus, R.S. 1982. 'Thoughts on the relations between emotion and cognition', American Psychologist, 37(9): 1019-1024.

Lazarus, R.S. 1984. 'On the primacy of cognition', American Psychologist, 39(2): 124-129.

Lazarus, R.S. 1991. Emotion and adaptation. New York: Oxford University Press.

Lerner, J.S. \& Tiedens, L.Z. 2006. 'Portrait of the angry decision maker: How appraisal tendencies shape anger's influence on cognition', Journal of Behavioral Decision Making, 19(2): 115-137.

Liao, C., Palvia, P. \& Lin, H. 2010. 'Stage antecedents of consumer online buying behavior', Electron Markets, 20(1): 53-65.

Machleit, K.A. \& Mantel, S.P. 2001. 'Emotional response and shopping satisfaction moderating effects of shopper attributions', Journal of Business Research, 54(2): 97-106.
Mauro, R., Sato, K. \& Tucker, J. 1992. 'The role of appraisal in human emotions: A cross-cultural study', Journal of Personality and Social Psychology, 62(2): 301317.

Maute, M.F. \& Forrester Jr., W.R. 1993. 'The structure and determinants of complaint intentions and behavior', Journal of Economic Psychology, 14(2): 219-247.

McConnell, A.R., Niedermeier, K.E., Leibold, J.M., ElAlayli, A.G., Chin, P.P. \& Kuiper, N.M. 2000. 'What if I find it cheaper someplace else?: Role of prefactual thinking and anticipated regret in consumer behavior', Psychology and Marketing, 17(4): 281-298.

McFarland, C. \& Ross, M. 1982. 'Impact of causal attributions on affective reactions to success and failure', Journal of Personality and Social Psychology, 43(5): 937946.

Newman, J.W. \& Werbel, R.A. 1973. 'Multivariate analysis of brand loyalty for major household appliance', Journal of Marketing Research, 10: 72-91.

Nunnally, J.C. 1978. Psychometric theory. New York: McGraw-Hill Book Co.

Oliver, R.L. 1987. 'An investigation of the interrelationship between consumer (dis) satisfaction and complaint reports', Advances in Consumer Research, 14(1): 218-222.

Ortony, A., Clore, G.L. \& Collins, A. 1988. The cognitive structure of emotions. Cambridge: Cambridge University Press.

Park, J.Y. \& Moon, S.J. 1990. 'A study on the consumer complaining behavior', Journal of Korean Home Management Association, 8(1): 15-30.

Roseman, I.J., Antoniou, A.A. \& Jose, P.E. 1996. 'Appraisal determinants of emotion: Constructing a more accurate and comprehensive theory', Cognition and Emotion, 10(2): 241277.

Russell, D. 1982. 'The causal dimension scale: A measure of how individuals perceive causes', Journal of Personality and Social Psychology, 42(6): 1137-1145.

Russell, D. \& McAuley, E. 1986. 'Causal attributions, causal dimensions, and affective reactions to success and failure', Journal of Personality and Social Psychology, 50(6): 1174-1185.

Sambandam, R. \& Lord, K.R. 1995. 'Switching behavior in automobile markets: A consideration sets model', Journal of the Academy of Marketing Science, 23(1): 57-65.

Schacter, S. \& Singer, J. 1962. 'Cognitive, social and physiological determinants of emotional state', Psychological Review, 69(5): 379-399. 
Schoefer, K. 2010. 'Cultural moderation in the formation of recovery satisfaction judgement: A cognitive-affective perspective', Journal of Service Research, 13(1): 52-66.

Singh, J. 1988. 'Consumer complaint intentions and behavior: Definitional and taxonomical issues', Journal of Marketing, 52(1): 93-107.

Smith, C.A. \& Lazarus, R.S. 1993. 'Appraisal components, core relational themes, and the emotions', Cognition and Emotion, 7(2): 233-269.

Tsiros, M. \& Mittal, V. 2000. 'Regret: A model of its antecedents and consequences in consumer decision making', Journal of Consumer Research, 26: 401-417.

Weiner, B. 1974. Achievement motivation and attribution theory. Morristown. NJ: General Learning Press

Weiner, B. 1985. 'An attribution theory of achievement motivation and emotion', Psychological Review, 92(4): 548573.

Weiner, B. 2000. 'Attributional thoughts about consumer behavior', Journal of Consumer Research, 27(3): 382-387.

Weiner, B., Russell, D. \& Lerman, D. 1979. 'The cognitionemotion process in achievement-related contexts', Journal of Personality and Social Psychology, 37(7): 1211-1220.

Wickens, C.M., Wiesenthal, D.L., Flora, D.B. \& Flett, G.L. 2011. 'Understanding driver anger and aggression: Attributional theory in the driving environment', Journal of Experimental Psychology, 17(4): 354-370.

Zeelenberg, M., Van Dijk, W.W. \& Manstead, A.S.R. 1998. 'Reconsidering the relation between regret and responsibility', Organizational Behavior and Human Decision Processes, 74(3): 254- 272.

Zeelenberg, M. \& Pieters, R. 2004. 'Beyond valence in customer dissatisfaction: A review and new findings on behavioral responses to regret and disappointment in failed services', Journal of Business Research, 57(4): 445-455.

Zeelenberg, M., Van Dijk, W.W., Manstead, A.S.R. \& Van der Pligt, J. 2000. 'On bad decisions and disconfirmed expectancies: The psychology of regret and disappointment', Cognition and Emotion, 14(4): 521-541.

Zinner, L.R., Brodish, A.B., Devine, P.G. \& Harmon-Jones, E. 2008. 'Anger and asymmetrical frontal cortical activity: Evidence for an anger withdrawal relationship', Cognition and Emotion, 22(6): 1081-1093.

Zucker, G.S. \& Weiner, B. 1993. 'Conservatism and perception of poverty: An attributional analysis', Journal of Applied Social Psychology, 23(12): 925-943. 